\title{
Obesity Increases Perioperative Complications after Elective Degenerative Posterior Lumbar Fusions: A Prospective Study
}

Rivkin MA* and Yocom SS

Department of Neurosurgery, Cooper University Hospital, 3 Cooper Plaza, Suite 104, Camden, NJ 08103, USA

\begin{abstract}
Study design: Prospective observational study of consecutive patients.

Objective: Body Mass Index (BMI) has recently been investigated for its association with adverse events during lumbar fusion surgery and remains a controversial issue. We attempt to evaluate the impact of BMI on the incidence of perioperative complications after elective, degenerative, posterior lumbar fusions in a surgery-naïve population.

Methods: We prospectively studied 77 consecutive patients undergoing open posterolateral lumbar fusion procedures at a single tertiary care center. Perioperative adverse events were defined by previously published reports and collected during the inpatient stay. Inclusion criteria reflected patients undergoing elective instrumented lumbar fusions while patients with revision surgery or history of infection, trauma or tumor were excluded from the study.

Results: There were 39 non-obese $(\mathrm{BMI}<30)$ and 38 obese $(\mathrm{BM} \mid>30)$ patients. Overall, $38 \%$ of patients suffered at least one complication. Forty one total complications occurred, $76 \%$ of those were minor and $24 \%$ were major complications. There was a significant difference in the rate of total complications between two groups with 13 adverse events in non-obese and 28 events in obese group $(p=.028)$. Using a backward elimination multivariate stepwise regression model based on maximum likelihood, obesity was an independent predictor of total complications $(p=0.02$, OR 1.082, 95\% confidence interval 1.012-1.157).

Conclusion: Lumbar fusion surgery is one of the most common spinal procedures and continues to be on the rise over the past decade. This prospective evaluation of patients undergoing elective degenerative lumbar fusions correlated obesity with increased incidence of total perioperative complications. These results argue for a more conservative approach and stringent surgical selection in obese patients.
\end{abstract}

Keywords: Obesity; Body mass index; Lumbar surgery; Perioperative complications; Prospective study; Lumbar fusion; Elective spinal surgery

\section{Introduction}

Back pain affects more than $80 \%$ of adults and is associated with treatment related cost of $\$ 20$ to $\$ 50$ billion every year in the U.S $[1,2]$ National trends demonstrate a 2.4 fold rise in spinal fusions and $490 \%$ increase in posterior lumbar fusions over the last decade $[2,3]$ The economic burden is further amplified by procedure-related postoperative complications. The cost of an adverse event in spinal surgery may reach $\$ 147,285$ depending on severity [4].

Incidence and types of adverse events during thoracolumbar surgery are well described in the literature and can reach $67 \%$ [59]. Numerous reports in spine literature attempt to investigate patient-related variables responsible for poor outcomes and higher complications [10-12]. Recently, body habitus received attention as a contributing factor associated with postoperative complicationsm [6,7,10,13-18] Body Mass Index (BMI) is an attractive target as an estimated 110 million Americans are either over-weight (BMI 25.029.9) or obese (BMI $\geq 30)$ [19-21]. Moreover, numerous technical challenges can present with elevated BMI in the surgical setting including difficulty with positioning, transport, imaging, venous and arterial access, perioperative airway management, and use of lipophilic anesthetics [22].

Although spine literature suggests a possible association between obesity and incidence of complications after lumbar procedures, it remains a contentious issue due to conflicting results from mostly retrospective analysis. This is further confounded by a multitude of surgery-related variables including the type of surgical pathology, presence of instrumentation, fusion versus decompression procedures, anterior versus posterior approaches, as well as inconsistent reporting of primary versus revision cases. A recent national insurance database review of trends in degenerative lumbar surgery identified posteriolateral lumbar instrumented fusions as $64 \%$ of all fusion surgery taking place in the US [23] Yet trials examining the impact of BMI on complication rate specifically during these procedures are scarce. Therefore, we prospectively investigated the association between BMI and perioperative complications in elective, open, lumbar surgery-naïve, posterolateral instrumented fusion cohort with degenerative pathology. To our knowledge, this is the first such report in the literature to date.

\section{Patients and Methods}

\section{Data collection}

The study was approved by our Institutional Review Board. This is a prospective, observational study of consecutive patients conducted at a single tertiary care center over an 18-month period (September, 2012 to March, 2014). All patients received the same operative and postoperative treatment that is currently considered the standard of

*Corresponding author: Mark A. Rivkin, Department of Neurosurgery, Cooper University Hospital, 3 Cooper Plaza, Suite 104,Camden, NJ 08103, USA, Tel: 215531-2275; Fax: 856-968-8697; E-mail: rivkin@comcast.net

Received June 18, 2015; Accepted July 22, 2015; Published July 25, 2015

Citation: Rivkin MA, Yocom SS (2015) Obesity Increases Perioperative Complications after Elective Degenerative Posterior Lumbar Fusions: A Prospective Study. J Neurol Disord 3: 240. doi:10.4172/2329-6895.1000240

Copyright: @ 2015 Rivkin MA, et al. This is an open-access article distributed under the terms of the Creative Commons Attribution License, which permits unrestricted use, distribution, and reproduction in any medium, provided the original author and source are credited. 
care at our institution. BMI was measured as part of the preoperative screening visit which took place three to five days prior to date of surgery. Complications were prospectively entered into the electronic medical record for each patient as they occurred from the date of admission through date of discharge.

The following inclusion criteria were used: age $\geq 18$, elective surgery, degenerative pathology (recorded as spondylolisthesis, scoliosis, stenosis, or primary disc pathology), and lumbar instrumented posterolateral fusion procedure. Exclusion criteria were prior lumbar surgery of any kind, history of tumor, infection, or trauma precipitating surgery, emergent procedures, and lumbar fractures. In addition to adverse events, variables such as age, gender, BMI, spinal levels of interest, estimated blood loss in milliliters (EBL), duration of procedure in minutes, and hospital Length Of Stay (LOS) were also recorded. BMI was reported in accordance with $\mathrm{NIH}$ guidelines: normal $<24.9$, overweight 25.0-29.9, obese 30.0-39.9, and morbidly obese $>40[14,20]$.

\section{Recording complications}

Adverse events were prospectively collected by members of the research team from the electronic medical record and independently validated by a blinded spine-trained nurse coordinator. In order to further combat potential includion bias, any event that was felt to be a perioperative complication by a single member of the research team was included in the final analysis. We used a broad definition of complications that has been previously validated and reported elsewhere to include any adverse events occurring in the perioperative setting [2426]. Events that did not impact the recovery time and resulted in no to minimal interventions were deemed minor complications. Events that required invasive interventions, delayed recovery, or prolonged the LOS were reported as major complications. Only events occurring during the inpatient setting were recorded for each patient.

\section{Statistical analysis}

Continuous variables such as age, surgery time, BMI and estimated blood loss were summarized using descriptive statistics (number of observations, mean, standard deviation, median and range) and compared between patients with no complications vs. 1 or more complications using a 1-factor analysis of variance model. To assess difference between obese and non-obese patients, a 1-factor analysis of variance model was used to compare the variables recorded on a continuous scale. Categorical parameters such as complications (yes or no) were compared between obese and non-obese patients using a 2 -tailed Fisher's exact test based on the hypergeometric distribution. A backward elimination multivariate stepwise regression model based on maximum likelihood was used to examine the effects of a variety of factors including the number of bones fused, operation time, age, number of hospital days, gender, BMI, and estimated blood loss on perioperative compliations. The objective of the model was to identify if any of the factors were predictive having a surgical complication. Probability values $<0.05$ were considered significant; values $<0.1$ but $>=0.05$ were considered highly suggestive of a significant difference. While additional cases would have increased the statistical power, the interest was to identify trends in the data. All results were calculated using SAS version 9.2 (Cary, NC).

\section{Results}

There were 77 total patients enrolled in the study with mean age of $52.2(\mathrm{SD}+14.1)$. Forty nine patients were female and 28 were male. The mean $\mathrm{BMI}$ for the entire population was 31.2. Mean surgical duration and EBL were 264 minutes (SD+63 min) and $347 \mathrm{~mL}(\mathrm{SD}+206 \mathrm{~mL})$, respectively. The average extent of fusion spanned 2.3 levels and patients were discharges after a mean of 3.7 days (Table 1). Overall, 29 of 77 patients (38\%) suffered at least one complication. In these 29 patients, 41 total adverse events were recorded with 31 minor (76\%) and 10 major (24\%) complications (Figure 1). Spinal stenosis was the most common preoperative diagnosis in both groups and there was no significant difference with respect to types of degenerative pathology treated (Table 1).

Thirty nine patients were classified as non-obese $(\mathrm{BMI}<30)$ while 38 were obese (BMI $>30)$. Age, gender, EBL, LOS, and number of spinal levels fused failed to reach significance between two arms (Table 1). Ten patients $(25.6 \%)$ in the non-obese group suffered a complication compared to $19(50 \%)$ in the obese group $(\mathrm{p}=.027)$. There was also a significant difference in the rate of total complications between the two groups with 13 adverse events in the non-obese and 28 events in the obese $(\mathrm{p}=.028)$. For the rate of minor complications, there was a highly suggestive association between BMI and obesity as 9 minor adverse events occurred in non-obese compared to 22 in the obese $(p=.091)$. The rate of major complications failed to reach a significant difference $(\mathrm{p}=.27)$.

We further examined the incidence and rate of complications by breaking the cohort into three groups: non-obese, obese (BMI 30.0-39.9), and morbidly obese (BMI $>40)$. There was an increase of complication incidence with rising BMI (Table 2). Twenty six percent

\begin{tabular}{|c|c|c|c|c|c|c|c|}
\hline & Total & SD & Non Obese & SD & Obese & SD & $P$ value \\
\hline Patients & 77 & & 39 & & 38 & & \\
\hline Ages & 52.2 & 14.1 & 54.7 & 13.4 & 49.5 & 14.4 & 0.094 \\
\hline Gender & $49 \mathrm{~F} / 28 \mathrm{M}$ & & $22 \mathrm{~F} / 17 \mathrm{M}$ & & $27 \mathrm{~F} / 11 \mathrm{M}$ & & 0.24 \\
\hline BMI & 31.2 & 7.7 & 25.5 & 3.4 & 37.1 & 6.3 & $<.001^{*}$ \\
\hline $\mathrm{EBL}(\mathrm{mL})$ & 347 & 206 & 351 & 240 & 343 & 167 & 0.87 \\
\hline $\begin{array}{l}\text { Case duration } \\
\text { (min) }\end{array}$ & 264 & 63 & 259 & 66 & 267 & 60 & 0.59 \\
\hline Levels fused & 2.3 & 1 & 2.1 & 1 & 2.4 & 1.1 & 0.21 \\
\hline LOS (days) & 3.7 & 1.5 & 3.5 & 1.3 & 3.9 & 1.6 & 0.31 \\
\hline $\begin{array}{l}\text { Pts with } \\
\text { complication }\end{array}$ & 29 & $38 \%$ & 10 & $26 \%$ & 19 & $50 \%$ & $.027^{*}$ \\
\hline \multicolumn{8}{|l|}{ Pathology: } \\
\hline Spondylolisthesis & \multicolumn{2}{|l|}{19} & \multicolumn{2}{|l|}{8} & \multicolumn{2}{|l|}{11} & 0.43 \\
\hline Scoliosis & \multicolumn{2}{|l|}{3} & \multicolumn{2}{|l|}{3} & \multicolumn{2}{|l|}{0} & 0.24 \\
\hline Stenosis & \multicolumn{2}{|l|}{34} & \multicolumn{2}{|l|}{18} & \multicolumn{2}{|l|}{16} & 0.82 \\
\hline Disc pathology & \multicolumn{2}{|l|}{21} & \multicolumn{2}{|l|}{10} & \multicolumn{2}{|l|}{11} & 0.81 \\
\hline
\end{tabular}

*Indicated Statistical Significance; BMI: Body Mass Index; EBL: Estimated Blood Loss in Milliliters; LOS: Length of Stay in Days; Min: Minutes

Table 1: Demographics separated by BMI.

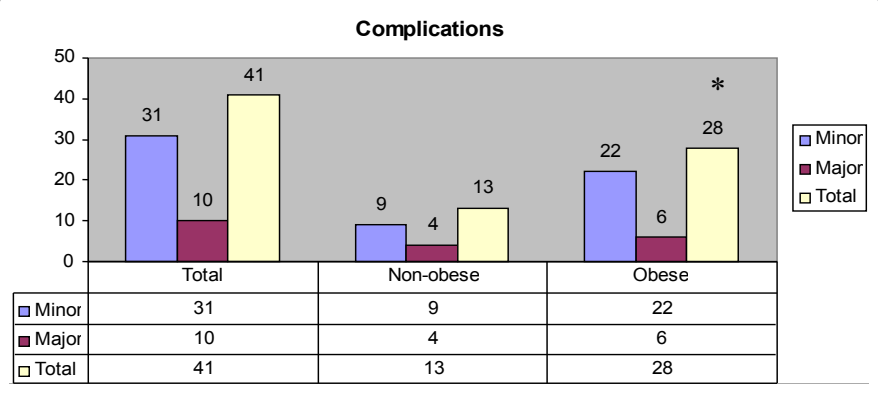

* - Denotes statistical significance. Comparison of complications between non-obese and obese patients reached statistical significance for total complications $(p=0.028)$ but not for minor or major complications, respectively $(p=0.091$ and $p=0.27)$

Figure 1: Complications. 
of non-obese patients had at least one adverse event compared to $41 \%$ and $73 \%$ in the obese and morbidly obese groups, respectively. This incidence reached statistical significance $(\mathrm{p}=0.018)$.

Summary of all encountered adverse events is provided in Table 3. In the non-obese group, the most common minor complications were superficial wound breakdowns and brief urinary retention, taking place in two patients each. Most common major complication was an incidental durotomy in three patients. In the obese group, positional neuropathies were most prevalent among minor adverse events and occurred in five patients. Hardware malposition not requiring return to the operating room occurred in three patients (Figure 2). Ileus and blood transfusions were reported in four patients each. Incidental durotomy was again the most common major complication in three obese patients. Two obese patients required a return to OR, one for an evacuation of epidural hematoma (Figure 3) with transient neurological deficit and another for a retained surgical drain. One obese patient experienced significant urinary retention requiring to be discharged with a urinary catheter for several weeks which was also considered a major complication.

Statistical factors influencing the risk of complications were further analyzed using multivariate logistic regression adjusting for BMI, EBL, operative duration, age, gender, number of levels fused, and LOS, using minor, major, and total compications as dependent variables. Logistic regression revealed that the probability of any complication (minor or major) was independently related to BMI ( $\mathrm{p}=.02$, OR $1.082,95 \%$ CI 1.012-1.157). Elevated BMI was suggestive of minor complications ( $p=.072$. OR 1.063, 95\% CI 0.994-1.137) while EBL was an independent predictor of such events ( $\mathrm{p}=.027$, OR 1.003, 95\% CI 1.000-1.005). Regression model for major complications demonstrated that age was highly suggestive of these events ( $p=.053$, OR $1.056,95 \% \mathrm{CI}$ $0.999-1.117$ ) but failed to identify any statistical significance for other variables.

\section{Discussion}

Incidence of perioperative adverse events in patients undergoing elective open lumbar fusions has a very broad range in the literature. Much of this can be attributed to the heterogeneity of studies exploring this issue. Variables such as anterior vs. posterior approach, thoracic vs. lumbar segments, decompression alone vs. fusion, surgical pathology, and proportion of revision procedures are highly inconsistent among published reports and have been demonstrated to independently affect complication rates $[6,8,27,28]$. This investigation attempts to eliminate bias by controlling for many of these confounding variables in order to establish a more accurate relationship between complication incidence and body habitus for a specific patient population. Consequently, we focused on a single procedure in a specific spinal segment. Furthermore, revision procedures, even at lumbar levels other than those treated in the study, were excluded. Next, only degenerative pathology as the primary diagnosis necessitating intervention was considered in order to include the vast majority of patients receiving surgery for chronic low back pain. Lastly, we investigated this issue prospectively. An extensive search of PubMed database for a combination of the following key terms "obesity, BMI, spinal surgery, lumbar, complications, and adverse events" did not reveal any journals matching all such criteria. To our knowledge, this is the first report prospectively investigating the effect of BMI on perioperative complications in a surgery-naive, degenerative, open lumbar fusion cohort.

The overall incidence of perioperative adverse events in the present study was $38 \%$. These findings are consistent with published data. The incidence of total complicaitons in prospective trials is reported to be as high as $53-67 \%$ for thoracolumbar fusion $[6-8,29]$. We demonstrated a significant difference in complication incidence between obese and non-obese groups with $50 \%$ and $26 \%$, respectively. We encountered almost twice as many patients experiencing a complications and more than twice the total complications in obese patients compared to those with $\mathrm{BMI}<30$, despite similar sample sizes in both groups. There were more of both minor and major adverse events in the obese group. Specifically, all three implant malpositions not requiring reoperation as well as both returns to the operating suite occurred in heavier patients. Further subdividing our cohort into three groups of non-obese, obese, and morbidly obese patients revealed a statistically significant rise in complication incidence with increasing BMI. Stepwise multivariate logistic regression was employed to evaluate for variables with significant effect on major, minor and total complications. Logistic regression revealed that BMI remained the only independent predictor of suffering any operative complication.

\section{Impact of obesity in retrospective studies}

There is paucity of literature evaluating the incidence of perioperative adverse events between obese and non-obese patients undergoing elective spinal fusions. Most available reports are retrospective in nature and include confounding variables such as multiple surgical approaches and revision surgery. Patel et al. retrospectively demonstrated that increasing BMI elevated the risk of significant postoperative complications after degenerative thoracolumbar procedures [14]. Seventy four of 84 patients received posterior lumbar decompression and fusion. However, $32.4 \%$ of those were performed through Minimally Invasive Surgical approach

\begin{tabular}{|l|l|l|l|}
\hline & Not Obese & Obese & MO \\
\hline Patients & 39 & 27 & 11 \\
\hline BMI mean & 25.5 & 33.9 & 44.9 \\
\hline Pt w/complication * & 10 & 11 & 8 \\
\hline Complications & \multicolumn{2}{|l|}{} \\
\hline Minor & 9 & 14 & 8 \\
\hline Major & 4 & 4 & 2 \\
\hline Total & 13 & 18 & 10 \\
\hline
\end{tabular}

*Denotes statistical significance. Based on the incidence, the 2-tailed probability from the Fiher's exact test was $p=0.0184$ comparing the number of patients with complications among three groups. Pt: Patients; MO: Morbidly Obese; BMI: Body Mass Index

Table 2: Comparing obese and morbidly obese patients.

\begin{tabular}{|c|c|c|c|}
\hline & & Non-obese & Obese \\
\hline \multirow[t]{9}{*}{ Minor } & Difficult/lost IV access & 1 & 2 \\
\hline & Atelectasis & 1 & 2 \\
\hline & lleus & 1 & 4 \\
\hline & Brief urinary retention & 2 & 1 \\
\hline & Blood transfusion & 1 & 4 \\
\hline & Positional neuropathy & 1 & 5 \\
\hline & Hardware malposition & - & 3 \\
\hline & Arrhythmia & - & 1 \\
\hline & Superficial wound breakdown & 2 & - \\
\hline \multirow[t]{4}{*}{ Major } & Durotomy & 3 & 3 \\
\hline & Return to OR & - & 2 \\
\hline & Urinary retention* & - & 1 \\
\hline & Pneumonia & 1 & - \\
\hline
\end{tabular}

*The patients went home with a urinary catheter after significant retention.

Table 3: Complications by type. 
Citation: Rivkin MA, Yocom SS (2015) Obesity Increases Perioperative Complications after Elective Degenerative Posterior Lumbar Fusions: A Prospective Study. J Neurol Disord 3: 240. doi:10.4172/2329-6895.1000240
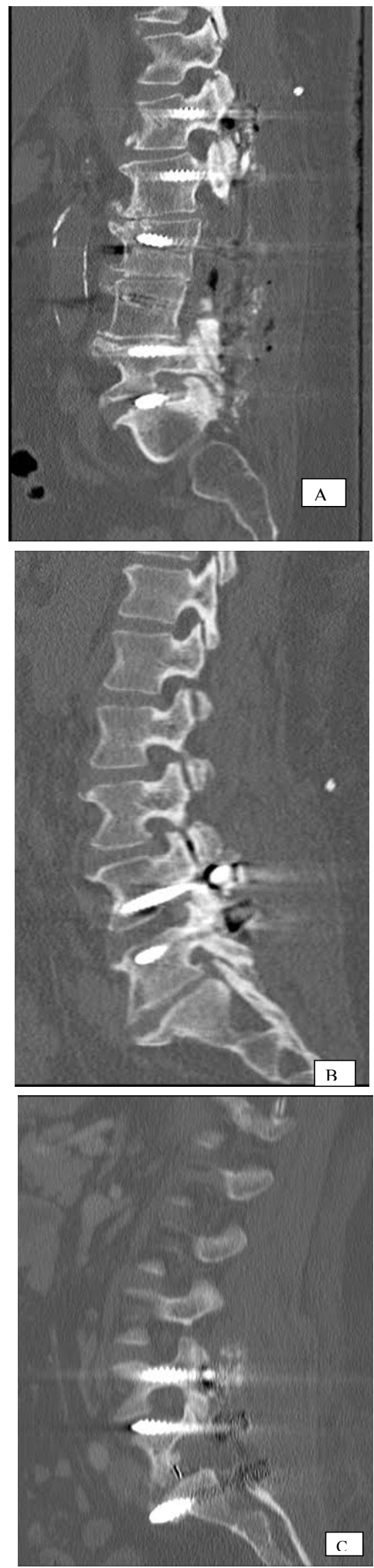

Figure 2: Hardware malpositions in three obese patients.

All three patients were not taken back to the operating room as the hardware location proved to be clinical silent. Preoperative leg symptoms improved in all three cases. A) 71yo female who underwent L1-S1 posterior instrumented fusion had a superiorly placed left $S 1$ screw into the L5/S1 disc space. B) 51 yo female who underwent L4-5 posterior instrumented fusion had a left inferiorly placed L5 screw. C) 47yo female that underwent L4-S1 posterior instrumented fusion with right superiorly oriented $L 5$ screw into the $L 4 / 5$ disc space.
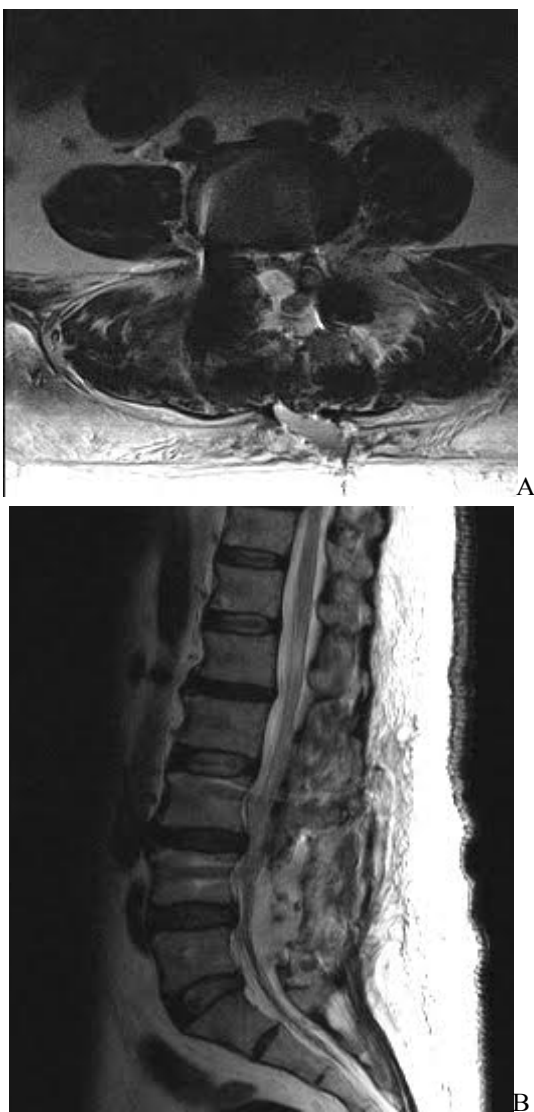

Figure 3: Postoperative epidural hematoma.

58yr female who underwent L3-5 posterior instrumented fusion developed $3 / 5$ bilateral dorsiflexion weakness on POD3 along with urinary retention. An MRI demonstrated a compressive epidural lesion in axial (2A) and sagital cuts (2B). She was emergently taken back to the operating room for evacuation of this lesion which proved to be a hematoma.

(MIS) while $26.7 \%$ were revision procedures [14]. Djurasovic et. al. retrospectively evaluated 270 obese and non-obese patients undergoing lumbar fusions [30]. Specific surgical approach was not mentioned and 53 patients were undergoing revision surgery. The authors reported a $17.4 \%$ incidence of adverse events in non-obese patients compared to $28.4 \%$ in obese [30]. Rihn et. al. correlated obesity with increased complication rates in a SPORT study subgroup analysis of 389 patients undergoing surgery for degenerative spondylolisthesis [17]. Instrumented fusions occurred in just $71.2 \%$ of patients and the number of revision procedures was not specifically mentioned [17]. The authors reported an increase in wound infections, unintentional durotomies, as well as four-year reoperation rates in obese patients. Shamji et. al. reviewed the Nationwide Inpatient Sample database and reported on 181,000 patients treated with thoracolumbar or lumbar fusion via a posterior approach for degenerative disease [31]. Neither proportions of open vs. MIS procedures nor the incidence of revision surgery was reported. Higher likelihood of transfusions and wound infections was observed in obese patients with posterior approach in this cohort. Similarly, Kalanithi et. al. offered a retrospective cross-sectional study of spinal fusions in California from 2003 to 2007 to investigate the impact of morbid obesity on outcome [12]. In total, 84,607 admissions were identified of which $42.1 \%$ were posterior lumbar fusions [12]. All diagnoses were included while surgical approaches or proportion of revision procedures were not reported. Morbid obesity was a significant predictor of in-hospital complication rate in this cohort. 


\section{Impact of obesity in prospective studies}

Prospective studies specifically evaluating the correlation between perioperative adverse events and body habitus for degenerative lumbar fusion surgery are even scarcer. We were able to identify only two such reports. Again, multiple surgical approaches and revision surgery were both included in the analysis. Contrary to present investigation, both studies failed to show a correlation between BMI and adverse events. Andreshak et. al. evaluated 159 consecutive patients with degenerative pathology of which 72 underwent a posterolateral fusion. Previous spinal surgery was reported in $29 \%$ of obese patients and $28 \%$ of nonobese [32]. Although the authors reported an overall complication rate of $16 \%$ in obese patients and $20 \%$ in non-obese, they failed to separate this by surgery type [31]. More recently, Yadla et. al. evaluated 87 patients following degenerative thoracolumbar surgery.7 The incidence of revision procedures was not reported and just $69 \%$ of patients underwent a fusion of any kind. Furthermore, only 24 patients (27.6\%) were treated with posterior lumbar instrumented fusion while others received either anterior or circumferential procedures [7].

\section{Economic burden of surgical complications}

Delineating patient-related factors responsible for perioperative complications in spinal fusion surgery may help to substantially reduce overall healthcare burden given that over 3.5 million fusions were recorded in the US over the past decade [33]. Whitmore et. al. evaluated the fiscal impact of perioperative complications after spinal surgery. Patients suffering a complication encountered an average cost increase of $\$ 13,714$ for major and $\$ 8,308$ for minor events [26]. Yet another study evaluating obesity and healthcare costs after lumbar fusion procedures reported a $\$ 20,092$ per-patient difference in total hospital charges between normal weight and morbidly obese patients secondary to higher in-hospital complications among the morbidly obese [12]. Most recently, 1,815 spinal surgery discharges form a tertiary center were analyzed for economic impact of adverse events. The authors reported a per-event financial burden for each complication ranging from $\$ 4,224$ to $\$ 147,285$ depending on severity [4].

\section{Alternatives to open lumbar surgery}

Given the potential economic impact of surgical complications, several alternative therapies have been beneficial for obese patients with low back pain and leg pain. Weight loss alone is effective in treating these symptoms as BMI is an independent predictor of low back pain $[30,34,35]$. Khoueir et. al. prospectively evaluated 58 patients with morbid obesity and chronic axial low back pain undergoing bariatric surgery. Significant weight reduction after bariatric surgery was associated with $44 \%$ reductions in preexisting back pain at 1 year as well as $58 \%$ increase in mean general health [36]. Most recently, Lidar et. al. prospectively investigated the effect of significant weight reduction on intervertebral disc space height, axial back pain, radicular leg pain, and quality of life in 30 morbidly obese patients [37]. The L4-5 disc space height increased from $6 \pm 1.3 \mathrm{~mm}$ preoperatively to $8 \pm 1.5$ $\mathrm{mm}$ at 1 year while both axial and radicular back pain significantly decreased after weight loss surgery [37]. Some surgeons hypothesize that surgical procedures aimed at alleviating back and leg pain wound potentiate weight loss in this population. Contrary to this, Vaidya et. al. followed obese and morbidly obese patients after a lumbar fusion for an average of 20.4 months and found that no weight loss occurred in the postoperative period [29].

MIS procedures serve as another alternative to open posterior lumbar fusion in heavier patients. A comparison of MIS versus standard transforaminal lumbar interbody fusion in an obese patient cohort yielded less EBL and shorter hospital length of stay [38]. More importantly, both total and intraoperative complications were significantly higher with the open approach [38]. Terman et al. offered a similar observation in their cohort of 74 obese patients. The authors reported clinically significant improvements for both MIS and open fusion groups of equal magnitude [39].

\section{Limitations}

There are several noteworthy limitations to our study. Although the sample size is consistent with previously published prospective reports in this area, larger sample would have greatly increased the statistical power of the analysis. The goal of present study was to investigate a trend between open lumbar fusions in degenerative surgery-naïve cohort and complication incidence. Certainly, larger trials need to be performed to confirm our results. We also offer no follow-up data with respect to complications beyond hospital discharge. This was intentionally done in the present study to account for lack of electronic medical records as well as consistency in reporting in the outpatient setting at our institution. Therefore, it was felt that numerous errors would be introduced had we attempted to measure complications beyond discharge. We concede that some postoperative adverse events, specifically wound infections, mostly present after hospital discharge and, as such, are not reflected in the current investigation. Lastly, contrary to previous reports, we found slightly increased EBL in non-obese patients. This was a surprising finding. We offer two hypotheses in this regard. First, perhaps the technical ease of surgery in smaller patients allowed for more extensive laminar and foraminal work leading to greater epidural venous and cancelous bone bleeding. Second, as we are a teaching facility perhaps more time was spent instructing and developing trainee technical skills in lighter patients, again secondary in part to perceived decrease of technical difficulty. This is further supported by the similarity in operative duration between the two groups in our series whereas most published reports describe less surgical time in skinnier patients.

\section{Conclusion}

The management of degenerative lumbar pathology in obese patients presents several challenges secondary to surgical positioning, transport, imaging, venous and arterial access, perioperative airway management, and spinal instrumentation. This prospective evaluation of surgerynaïve patients undergoing elective degenerative lumbar fusions correlated obesity with increased incidence of total perioperative complications. Healthcare expenditures associated with complications in the context of this report suggest more stringent selection criteria in the obese and morbidly obese population. We do not advocate withholding surgical interventions based solely on BMI parameters as good long-term clinical outcomes have been demonstrated in carefully selected obese patients $[17,34]$. However, given the growing association of adverse events and BMI during degenerative lumbar fusions, surgery should be reserved for cases where extensive conservative therapy has been exhausted and weight loss measures been undertaken. The surgeon should be prepared to encounter perioperative complexities, potentially longer procedure times and blood loss. It is prudent to thoroughly address these issues with patients in addition to the standard discussion taking place during surgical consent process.

\section{References}

1. Mirtz TA, Greene $L(2005)$ Is obesity a risk factor for low back pain? An example of using the evidence to answer a clinical question. Chiropr Osteopat 13: 2.

2. Cheng JS, Vohra KP, Wong CC, McGirt MJ (2013) The future of the use of spine surgery. Neurosurgery 60 Suppl 1: 34-40. 
Citation: Rivkin MA, Yocom SS (2015) Obesity Increases Perioperative Complications after Elective Degenerative Posterior Lumbar Fusions: A Prospective Study. J Neurol Disord 3: 240. doi:10.4172/2329-6895.1000240

3. Rajaee SS, Bae HW, Kanim LE, Delamarter RB (2012) Spinal fusion in the United States: analysis of trends from 1998 to 2008. Spine (Phila Pa 1976) 37: 67-76.

4. Hellsten EK, Hanbidge MA, Manos AN, Lewis SJ, Massicotte EM, et al. (2013) An economic evaluation of perioperative adverse events associated with spinal surgery. Spine J 13: 44-53.

5. Nasser R, Yadla S, Maltenfort MG, Harrop JS, Anderson DG, et al. (2010) Complications in spine surgery. J Neurosurg Spine 13: 144-157.

6. Yadla S, Malone J, Campbell PG, Maltenfort MG, Harrop JS, et al. (2010) Early complications in spine surgery and relation to preoperative diagnosis: a singlecenter prospective study. J Neurosurg Spine 13: 360-366.

7. Yadla S, Malone J, Campbell PG, Maltenfort MG, Harrop JS, et al. (2010) Obesity and spine surgery: reassessment based on a prospective evaluation of perioperative complications in elective degenerative thoracolumbar procedures. Spine J 10: 581-587.

8. Campbell PG, Malone J, Yadla S, Maltenfort MG, Harrop JS, et al. (2010) Early complications related to approach in thoracic and lumbar spine surgery: a single center prospective study. World Neurosurg 73: 395-401.

9. Campbell PG, Malone J, Yadla S, Chitale R, Nasser R (2011) Comparison of ICD-9-based, retrospective, and prospective assessments of perioperative complications: assessment of accuracy in reporting. J Neurosurg Spine 14: 16-22.

10. Pull ter Gunne AF, Cohen DB (2009) Incidence, prevalence, and analysis of risk factors for surgical site infection following adult spinal surgery. Spine (Phila $\mathrm{Pa}$ 1976) 34: 1422-1428

11. Pumberger M, Chiu YL, Ma Y, Girardi FP, Mazumdar M, et al. (2012) National in-hospital morbidity and mortality trends after lumbar fusion surgery between 1998 and 2008. J Bone Joint Surg Br 94: 359-364.

12. Kalanithi PS, Patil CG, Boakye M (2009) National complication rates and disposition after posterior lumbar fusion for acquired spondylolisthesis. Spine (Phila Pa 1976) 34: 1963-1969.

13. Hanigan WC, Elwood PW, Henderson JP, Lister JR (1987) Surgical results in obese patients with sciatica. Neurosurgery 20: 896-899.

14. Patel N, Bagan B, Vadera S, Maltenfort MG, Deutsch H, et al. (2007) Obesity and spine surgery: relation to perioperative complications. J Neurosurg Spine 6: 291-297.

15. Peng CW, Bendo JA, Goldstein JA, Nalbandian MM (2009) Perioperative outcomes of anterior lumbar surgery in obese versus non-obese patients. Spine J 9: 715-720.

16. Shiri R, Karppinen J, Leino-Arjas P, Solovieva S, Viikari-Juntura E (2010) The association between obesity and low back pain: a meta-analysis. Am J Epidemiol 171: 135-154.

17. Rihn JA, Radcliff K, Hilibrand AS, Anderson DT, Zhao W, et al. (2012) Does Obesity Affect Outcomes of Treatment for Lumbar Stenosis and Degenerative Spondylolisthesis? Analysis of the Spine Patient Outcomes Research Trial (SPORT). Spine (Phila Pa 1976) 37: 1933-1946.

18. McClendon J Jr, Smith TR, Thompson SE, Sugrue PA, OÊ1/4shaughnessy BA et al. (2014) The impact of body mass index on hospital stay and complications after spinal fusion. Neurosurgery 74: 42-50.

19. Fanuele JC, Abdu WA, Hanscom B, Weinstein JN (2002) Association between obesity and functional status in patients with spine disease. Spine (Phila $\mathrm{Pa}$ 1976) 27: 306-312.

20. Flegal KM, Carroll MD, Kuczmarski RJ, Johnson CL (1998) Overweight and obesity in the United States: prevalence and trends, 1960-1994. Int J Obes Relat Metab Disord 22: 39-47.
21. Ogden CL, Carroll MD, Kit BK, Flegal KM (2012) Prevalence of obesity and trends in body mass index among US children and adolescents, 1999-2010. JAMA 307: 483-490.

22. Rosenfeld HE, Limb R, Chan P, Fitzgerald M, Bradley WP, et al. (2013) Challenges in the surgical management of spine trauma in the morbidly obese patient: a case series. J Neurosurg Spine 19: 101-109.

23. Pannell WC, Savin DD, Scott TP, Wang JC, Daubs MD (2015) Trends in the surgical treatment of lumbar spine disease in the United States. Spine J 15 1719-1727.

24. Lebude B, Yadla S, Albert T, Anderson DG, Harrop JS, et al. (2010) Defining "complications" in spine surgery: neurosurgery and orthopedic spine surgeons' survey. J Spinal Disord Tech 23: 493-500.

25. Ratliff JK, Lebude B, Albert T, Anene-Maidoh T, Anderson G, et al. (2009) Complications in spinal surgery: comparative survey of spine surgeons and patients who underwent spinal surgery. J Neurosurg Spine 10: 578-584.

26. Whitmore RG, Stephen J, Stein SC, Campbell PG, Yadla S, et al. (2012) Patient comorbidities and complications after spinal surgery: a societal-based cost analysis. Spine (Phila Pa 1976) 37: 1065-1071.

27. Baker GA, Cizik AM, Bransford RJ, Bellabarba C, Konodi MA, et al. (2012) Risk factors for unintended durotomy during spine surgery: a multivariate analysis. Spine J 12: 121-126.

28. Eichholz KM, Ryken TC (2003) Complications of revision spinal surgery Neurosurg Focus 15: E1.

29. Vaidya R, Carp J, Bartol S, Ouellette N, Lee S, et al. (2009) Lumbar spine fusion in obese and morbidly obese patients. Spine (Phila Pa 1976) 34: 495-500.

30. Djurasovic M, Bratcher KR, Glassman SD, Dimar JR, Carreon LY (2008) The effect of obesity on clinical outcomes after lumbar fusion. Spine (Phila Pa 1976) 33: 1789-1792.

31. Shamji MF, Parker S, Cook C, Pietrobon R, Brown C, et al. (2009) Impact of body habitus on perioperative morbidity associated with fusion of the thoracolumbar and lumbar spine. Neurosurgery 65: 490-498.

32. Andreshak TG, An HS, Hall J, Stein B (1997) Lumbar spine surgery in the obese patient. J Spinal Disord 10: 376-379.

33. Goz V, Weinreb JH, McCarthy I, Schwab F, Lafage V, et al. (2013) Perioperative complications and mortality after spinal fusions: analysis of trends and risk factors. Spine (Phila Pa 1976) 38: 1970-1976.

34. Knutsson B, Michaëlsson K, Sandén B (2013) Obesity is associated with inferior results after surgery for lumbar spinal stenosis: a study of 2633 patients from the Swedish spine register. Spine (Phila Pa 1976) 38: 435-441.

35. Smuck M, Kao MC, Brar N, Martinez-Ith A, Choi J, et al. (2014) Does physical activity influence the relationship between low back pain and obesity? Spine J 14: 209-216.

36. Khoueir P, Black MH, Crookes PF, Kaufman HS, Katkhouda N, et al. (2009) Prospective assessment of axial back pain symptoms before and after bariatric weight reduction surgery. Spine J 9: 454-463.

37. Lidar Z, Behrbalk E, Regev GJ, Salame K, Keynan O, et al. (2012) Intervertebra disc height changes after weight reduction in morbidly obese patients and its effect on quality of life and radicular and low back pain. Spine (Phila Pa 1976) 37: 1947-1952.

38. Lau D, Khan A, Terman SW, Yee T, La Marca F, et al. (2013) Comparison of perioperative outcomes following open versus minimally invasive transforaminal lumbar interbody fusion in obese patients. Neurosurg Focus 35: E10.

39. Terman SW, Yee TJ, Lau D, Khan AA, La Marca F, et al. (2014) Minimally invasive versus open transforaminal lumbar interbody fusion: comparison of clinical outcomes among obese patients. J Neurosurg Spine. 